\title{
Discussion on the Personality Differences and Development of Student in Physical Education
}

\author{
Mingyue $\mathrm{Zhu}^{1, \mathrm{a}}$ \\ ${ }^{1}$ Tianjing University of Finance and Economics \\ amingyue_my@126.com
}

Keywords: Physical education, Structural reform, Students personality differences and development

\begin{abstract}
Through in-depth implementation of the strategy of priority to talent development, to build up China to a powerful country by talents, to take the talent development and structural reform as the first step for the reform of personnel system reform and to push the policy innovation, which is one of the most important planning in our country. The importance of talent goes without saying.This article, through the Liuhe analysis method and reference from various major literatures, takes comparison of individual differences of today's university and college students who are faced with physical education,makes annotation of the significance of personality development, as well as how to carry out physical education system reform and make students be the talents meeting the national demand in the new century.
\end{abstract}

\section{Introduction}

In today with the implementation of quality education, the talents that society needs are individualistic and innovative. Physical education is to ensure the students' physical health by way of physical exercise, make students personality get a good development, and let students adapt to college life better. Student-oriented education way is the fundamental of today's quality education in colleges and universities, however directing at students' individual differences, how to develop the students' personality becomes a problem that colleges and universities have to face.The reform of physical education is deepening, at the same time guaranteeing the students' physical quality, we should develop students' personality.As physical education teachers, they should improve their teaching ability, improve their teaching methods and teaching content and let the students' individuality get development and own stronger competitivenessin in future social life

\section{Factors Influencing Students’ Personality in Physical Education}

Perfect physical education equipment and elegant and clean physical site will make the students be in a comfortable physical education environment;Student collective with mutual solidarity and mutual help and enthusiastic and positive teaching atmosphere will increase students' enthusiasm in participating in the activities of physical teaching and promote the student's focus in the classroom.

In adolescents' self development, the desire for the social activities and the self-identity from the society is very strong. It is necessary to build a complete collective, and let every student own the belonging sense of the collective.Therefore, the existence of the collective will let students directly face the differences with other people, so it is very importantmake for students develop their own 
personality.

Everyone's enthusiasm for all kinds of behavior about different things is from the influence of a motivation, and the reason for that motivation is people's need.This demand will encourage people to struggle and stride forward for certain aim.Physical education can cultivate the comprehensive quality of students by promoting the students' need, and then let the students overcome difficulties and achieve self-transcendence.

\section{The Meaning of Developing Students’ Individuality in Physical Education}

A person's individual thought, emotion, personality, faith, quality, willpower, emotion, attitude, behavior and values are different from other people's speciality, which is generally called personality.As a result of the existence of personality, it allows us to see clearly the difference between ourselves and the others,however, this kind of personality is going in constant change and continuous evolution, when one begins to perceive the outside things, all these experiences will become the factors affecting the person's individuality.Everyone is a part of society, and the formation of personality has a close realtion with the process of human's becoming a part of the society. Either the original quality in parents' genes, or human bad behavior influenced by living environment of people, or information got through the media information, are all the factors for individuality formation.

In physical sports, the most obvious characteristic is the competition consciousness. Through the activities of quality developing games etc. in classroom to improve students' competitive consciousness. And this competition consciousness will become a precious wealth after students entering into society

Independent consciousness is a kind of consciousness that contemporary college and university students generally lack.In physical competition, students often need to face the pressure from competition by themselves and constantly under this pressure environment, college students will force themselves to change their character of depending on others immediately when they encounter problems.In the process of overcoming the resistance given by environment, students will own stronger independent consciousness. Therefore, leting the student be in the competitive environment is one of the best platform of training students' independent consciousness.

Both the report from major news media and various domestic research institutions have shown that the physical quality of Chinese citizens is decreasing year by year. The decreasing of our country's citizen physical quality is influenced by various factors, and in these factors, our citizens' neglect for health and physical education is the most important aspect which can not be ignored. The indifference to physical education consciousness makes this situation more serious year by year. School is the training base for talents, however the talents without health do not make any sense.So cultivating college and university students' lifetime physical education consciousness and letting them form the good habit of lifetime exercise, is one urgent problem needing to be faced for the deepening reform of physical education teaching.

After finishing enclosed high school life, the openness of university life, may make some students feel unaccommodated.Physical education teaching, relative to traditional education, is more similar to a kind of outdoor activity, which lets part of students with social difficulties actively communicate with others to form normal social thought and social attitudes,and then make their various ability of adapting to various aspects in society. 


\section{Cognition of Students’ Individual Difference}

As the physical education teacher, they must clearly know their students' individual character, observe students in physical education activities and deepen their understanding of the students.In the time of the implementation of physical education, if the students are treated in the same way, it is hard to work, besides,the class time is shorter, it is not possible to adopt different teaching plan according to each student's individual differences .

In the real physical education teaching activities, each teaching habit and living habit of physical education teachers will influence his students in different degrees. Therefore, physical education teachers' good self-cultivation and individual quality have a significant impact on cultivating the good personality for good students. How to cultivate physical education teachers' self-cultivation and individual qualities? We should pay attention to the following three aspects:

A Interest. As the physical education teacher, they should be full of interests in physical education teaching. According to their own characteristics, learn more knowledge related to physical education. In class, they can carry out various interesting physical education activities; Psychologically, make it clear that what is the meaning of sports education.

B Willpower. In order to achieve certain purpose, you should keep a a state of mind that no matter what difficulties you face, do not give up, which is often expressed with words and actions.A teacher who takes education career as the responsibility of his life, and no matter what difficulty or setback he meet, he won't give up. This firm faith will be an example for the students.

Innovation. Education, in some ways, is the activity of creating future. The emergence of innovative activities in physical education class, can expand students' thinking and make them more active energetic to learn and also promote the development of their personality.

The key of Heuristic method of teaching lies in how to obtain knowledge by independent thinking and practice. When the teachers give lessons to the students, they should let the students think independently to complete the task by asking questions but do not make any explanation.In the student's thinking of myth or choose the wrong direction, teachers can take simple reminder. When the students come into the wrong region of thinking or choose a wrong direction, the teachers can give simple hint. After the students master the methods of solving the problem preliminarily, teachers can improve the difficulty of the problem, or stimulate students' intestest in learning in the form of competition between students and let students be more active.

Learning-leading teaching method is one method for self-study under the guidance of teachers.Firstly, learning-leading is implemented in the precondition that students have a certain ability to study independently and teacher has a good ability to guide.Secondly, in the process of students' self-study, they should learn with direction and destination according to teacher's request. Then, when students, in the process of self-study, are aced with problem, the teachers should interact and discuss with students actively to solve the problem. Finally, let the students themself sum up the methods of self-study.

Self-discovery teaching method is the method that teacher,by providing problem or design environment, lets the student creat question when they face problems, and according to the requirements put by teachers, make the students explore the method of solving the problem. Then, let the studetns master the basic principles of the sports skills in the process of practice. Later, the teachers continue to organize students to put forward their own ideas in view of the questions, and take verification in practice. Finally, teachers make summary on the basic principle of sports skills and students' idea. Taking the basketball course in college and university as one example, before the teacher starting teaching, he can put forward the purpose of this course,and do not teach students specific dribbling and shooting skills, but require students to summarize the shooting and dribbling 
skills.Let the student constantly improve their own methods by repeated practice. Finally, the teacher can organize the students to carry on discussion, and express their own thoughts on dribbling and shooting, and then let the students master the skills further. Facing the objection and different ideas put by students, teachers can not be eager to deny, but to explore the solutions together with the students.

\section{Structural Reform of Physical Education}

Taking the cultivation of students' comprehensive quality and physical education fitness consciousness as the goal and do not separate exercise with the whole of physical education.With the progress of science and technology, the development of society and the booming development of leisure sports, fun sports, entertainmen sports etc., the teaching content should have more innovative courses, and add more public sports curriculum that one would like to see and hear,such as aerobics, hip-hop, roller skating etc.

The reform of education form is the key of reform of teaching content,and in order to realize new education goal, it is necessary to take reform of teaching form.First of all, turn students' passive learning into active learning. Under the same education target, according to different teaching content, to design the most suitable teaching course for students. The role of teachers should be macro-control role, and give students the opportunity of full autonomous right and developing innovative thinking. On the premise of not deviating from the education target, let students play their best possibilities.Second, it is also important to take extracurricular sports, establish sports clubs and give the student independent right to choose and participate.

Under the premise of physical education teaching in the universities and colleges, the physical education teachers can use the above mentioned heuristic method,learn-leading method and self-discovery teaching method to independently design teaching curriculum and make the physical education teaching be both scientific and interes.

In foreign countries, the teachers of physical education evaluation curriculum make scores for the students' performance in physical education curriculum combined with the process evaluation and result evaluation.At home, the physical education evaluation course in many colleges and universities only attach importance to the final result. The practice has proved that only depending on the results to evaluate phesical education has little practical significance.If only taking the result evaluation method, then, students will lose enthusiasm in the process of physical education teaching. Therefore, combining the two kinds of evaluation methods is the mainstream of modern education evaluation.

\section{Conclusion}

In physical education, the students' individual differences are obvious, and the development of students personality is very important, under this kind of contradiction, the reform of physical education system is inevitable.In the increasingly fierce social competition, we need to understand deeply the significance of the strategy of human resource development reinvigorating a country,and take scientific method for physical education system reform. Physical education teachers take appropriate methods to develop physical education teaching and directing at the students' individual differences, to develop students' individual character, then the difference will not be harmful to physical education teaching, but can promote students' personality.Finally, directing at the actual situation that school face to take different reform methods through a variety of physical education system reform is the final choice for the development of physical education 
career.

\section{References}

[1] Rujin Liu,Discussion on the Methods of Developing Student Individuality in PE Teaching[J].Physical Education,2002(16):71-73

[2] Cuihong Zhang,Development of Student's Personality in Physical Education Teaching[J].Journal of Xinxiang College of Education,2004(01).

[3] Chuanyin Cheng,Discussion on the Development of Student's Personality in Physical Education Teaching[J].Journal of Nanjing Sport Institute（Social Science）,2003(21):46-49

[4] Huanyang Han, Development of Student's Personality and Reform of Physical Education Teaching[J].Journal of Liaoning Police Academy,2003(05).

[5] Xiudong Du, Discussion on Physical Education System Reform in College and University[J]Sports Culture Guide,2001(01)

[6] Yimin Zhou,Guiding for Physical Education Teaching in Secondary Vocational School by Taking 'Self-Discovery Method'[J]. China Extramural Education,2015,18:147-148.

[7] Juting Yan,XinliDang,Self-Awakening:Discussion on Teachers' Individualized Teaching[J].Journal of Jilin Institute of Education,2011,03:61-63.

[8] Hongbin Liang, Development of Students'Personality in College and University Physical Education Teaching[J].Hebei Business Press,2014. 